ORIGINAL ARTICLE

\title{
The feelings \& perceptions of a Medical doctor after recovery from Corona infection
}

\author{
SIDRAH RIAZ ${ }^{1}$, SABRINA TARIQ ${ }^{2}$, UMAIR TARIQ MIRZA ${ }^{3}$, MUHAMMAD TARIQ KHAN ${ }^{4}$, SHABANA CHAUDHARY ${ }^{5}$, \\ MUHAMMAD ARSHAD ${ }^{6}$ \\ ${ }^{1}$ Associate Professor of Ophthalmology, Akhtar Saeed Medical and Dental College, Lahore \\ ${ }^{2}$ House Officer, Department of Dentistry, Combined Military Hospital (CMH) Lahore \\ ${ }^{3}$ Assistant Professor Ophthalmology, Muhiuddin Islamic Medical college, Mirpur AJK \\ ${ }^{4}$ Professor of Ophthalmology, Akhtar Saeed Medical and Dental College, Lahore \\ ${ }^{5}$ Assistant Professor Ophthalmology, Mayo Hospital, Lahore \\ ${ }^{6}$ Assistan Professor Ophthalmology, BVH, Bahawalpur \\ Correspondence to Dr. Sidrah Riaz, Email.sidrah893@yahoo.com,+92-0322-4367303
}

\begin{abstract}
Aim: To know the core feelings and perception of a medical doctor after recovery from corona infection

Study Design: A descriptive cross-sectional qualitative survey

Place and duration of study: Akhter Saeed medical and dental college Lahore. Duration of study was two months from $1^{\text {st }}$ January 2021 to $31^{\text {st }}$ March 2021.

Methods: A survey questionnaire is formed and sent to different doctors of different specialties both in the public and private sectors. Non-probability conventional sampling technique was used. Qualitative data was analyzed by the SPSS 20.

Results: The online survey was sent to three hundred and fifty (350) doctors who were fellows, consultants, assistant consultants and professors. The voluntary response is submitted by 26 doctors who suffered and recovered from corona infection.

Conclusion: Coronapandemic has physical, psychological, social and economic effects. Everyone who suffered from it has his own insight about disease but unlike other infections, anxiety and uncertainty about future were major psychological effects which added to physical suffering of patients. All recovered patients strongly recommended following of SOPs. Vaccinationwith following SOPs is unanimously only optimistic approachagainst corona to decrease incidence and severity of infection. There is a need for doctor counselling sessions to cope with stress and anxiety issues.
\end{abstract}

Keywords: Corona infection, anxiety, consultant.

\section{INTRODUCTION}

Corona has emerged as new health hazard worldwide associated with immense loss of lives, exhaustion of money resources and mental strains. It is a viral disease which appeared initially in Hubei province of China in November 2019 and first reported to WHO as pneumonia of unknown cause in December 20191-3. Later it was confirmed in other regions outside china as well like in Thailand, Taiwan, Italy and Europe. According to reports 213 countries of the world have been knocked down with this dilemma with 430,000 deaths and 7.76 million active cases $^{4,5}$.

Pakistan is adversely affected with the pandemic because of number of factors including poor infrastructure of health, limited resources, illiteracy, deeply rooted myths and non-serious attitudes towards following of SOPs advised by health advisors ${ }^{6}$.

The Health care providers are at greater risk of contracting infections. About 14,627 doctors, nurses, and other health workers in Pakistan have been infected with the coronavirus. Out of which 143 have succumbed to the disease so far.The highest number of health professionals are infected with coronavirus is from Sindh. According to a document provided by the Ministry of National Health Services, a total of 14,627 health workers in Pakistan have

Received on 02-04-2021

Accepted on 18-05-2021 been infected by COVID-19 so far, including 8,588 doctors, 2,177 nurses, and 3,862 other health workers ${ }^{7}$.

Till date in Pakistan nearly 152 Doctors have lost their lives, excluding paramedical staff. As aerosol,through the respiratory route, is main route of transmission of infection, doctors from certain specialties like Dentists, ENT surgeons, Ophthalmologists, Dermatologists are more prone to exposure of infection ${ }^{8,9}$.

\section{MATERIAL AND METHODS}

A questionnaire was formed and sent to doctors who were specialists, fellows, professors, consultants and assistant consultants working actively as physician or surgeons. It consisted of fifteen (15) questions that were sent to consultants by post, email and on social media. It was conducted nearly one year after first case declaration in Pakistan. Online survey methodology was used. Online google survey was generated and sent to those eye specialists who had computer literacy. Non-probability conventional sampling method was used. The doctors who didn't had fellowship degree, qualified but not doing private practice were excluded from study. The interview-based data collection technique was also formulated for those who were not very well worse in computer use. The data collected was cleaned, codded and entered in SPSS version 20. The frequency tables were generated, and qualitative variables were presented in form of pie charts and bar charts. 


\section{RESULTS}

Out of 350 specialist doctors belonging to different fields of surgery and medicine, 26 submitted their response who recovered from corona by their own will to share their views. The age range of affected doctors was 35 to 63 yeas with an average age 50.8 years. These doctors belong to different specialties like medicine, surgery, ophthalmology, gynecology, community medicine, dentistry, neurology, orthopedic and pathology. $23.80 \%$ consultants were vaccinated already with corona vaccine at time of diagnosis where as $76.20 \%$ were not vaccinated when got infection (Fig 1).The time duration between vaccination and getting corona infection symptoms ranged from 2 to 21 days after first dose where as in one person it was 10 days after $2^{\text {nd }}$ dose of vaccine. The different vaccines used were Chinese vaccine sinopharm for majority of doctors $(83.20 \%)$ and $5.6 \%$ had sputnik, $5.6 \%$ had Pfizer and $5.6 \%$ has vaccination with AstraZeneca (Fig2). All doctors were using protective measures specially face masks $(100 \%)$. Close family member living under same roof were also positive in $68.20 \%$ cases where as only doctor was corona positive in $31.80 \%$ cases and family was spared(Fig 3$)$. Hospitalization was required for disease complication in $9.10 \%$ cases whereas $90.90 \%$ were treated at their homes under physician guidance (Fig4). The duration of hospitalization was 10 days to two weeks. Regarding day offs from a work place was minimally 7 days to maximum 45 days but on an average most doctors had 2 weeks off from work places. Antiviral drugs with steroids were part of treatment regime for $59.10 \%$ and $40.90 \%$ recovered without antiviral therapy(Fig 5).Top four reactions after getting positive corona test were anxiety $(40.60 \%)$, sense of insecurity $(14.20 \%)$, fear (13.60\%) and depression in $9.10 \%$ (Fig 6. Bar chart). Isolation (54.50\%) was one thing which bothered most of consultants during illness; others were economic strain $13.60 \%$ and mental health9.10\%.Other bothersome aspects were anxiety, severe myalgia, weakness, children jobs and marriages and depressive thoughts, $4.5 \%$ for each (Fig 7. Bar chart).

Fig 1:vaccination status

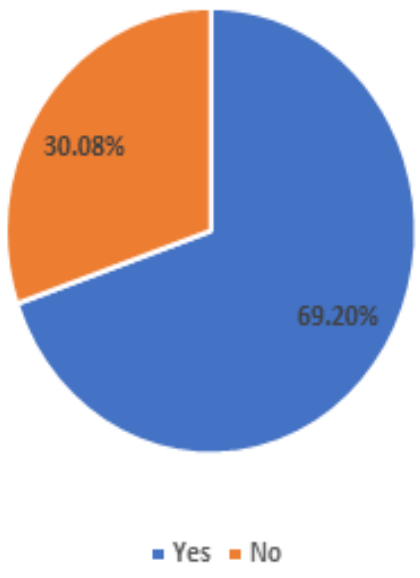

Fig 2: type of vaccine used

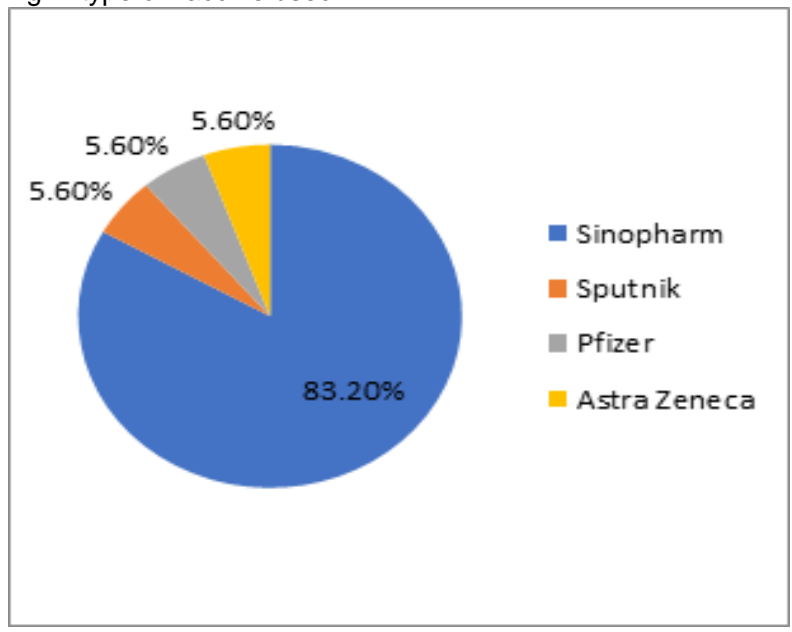

Fig 3: corona test positive in family members

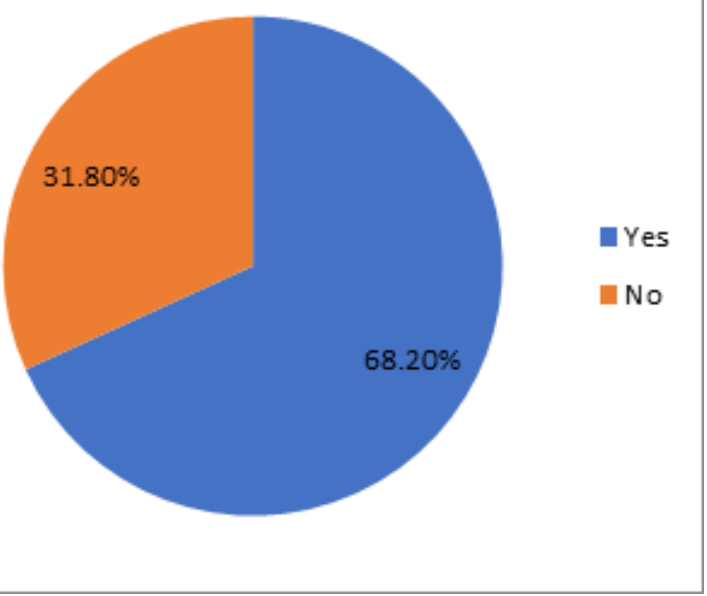

Fig 4: Hospitalization admission required or not

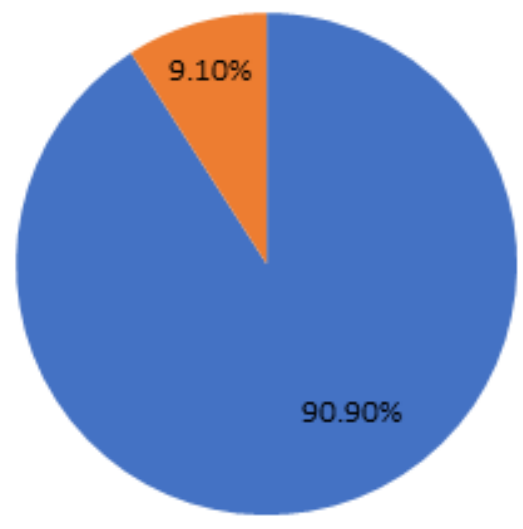

No

Yes 
Fig 5: antiviral/steroids used or not

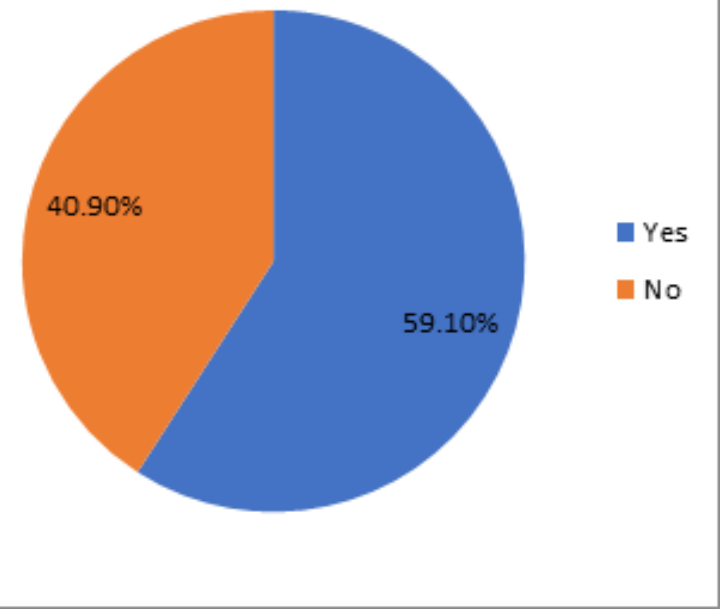

Fig 6: First thought in mind when corona test found positive

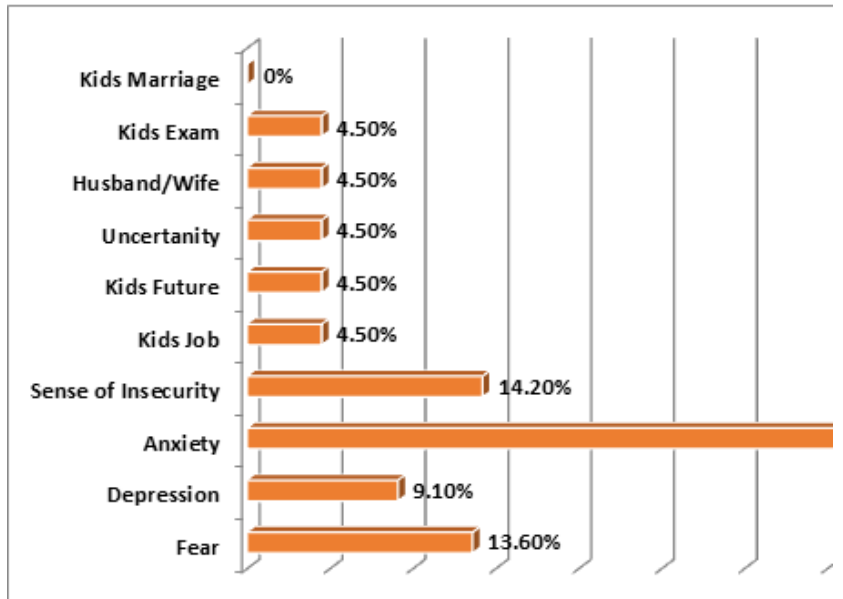

Fig 7: Most bothered aspects during illness

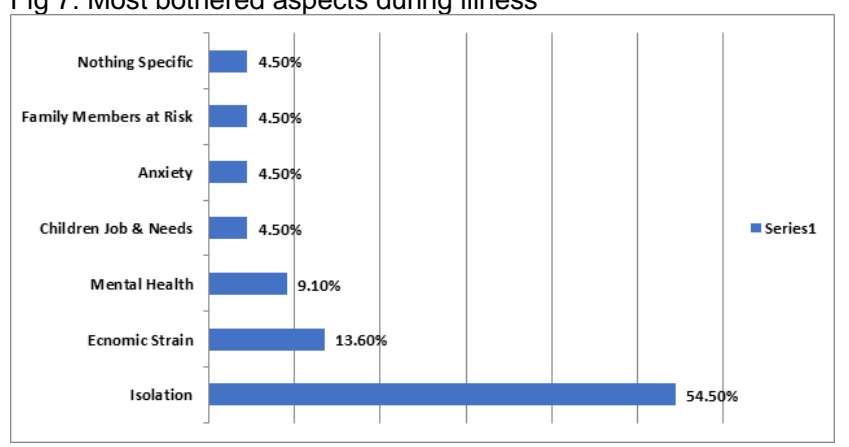

\section{DISCUSSION}

Corona pandemic has created lot of psychosocial issues, apprehension, unease and restlessness for the human beings and health care workers are not different. The universal approach of social distancing, self-isolation and lockdown has been adopted to control disease spread ${ }^{10}$. Closure of educational institutes, $50 \%$ attendance at offices, avoiding elective surgeries and social gathering restrictions are implemented by higher authorities.

Pakistan is a populous country with 212 million people and here doctor to patient ratio is low 1:1300 ${ }^{11}$.Pakistan health system is not very strong and its capacity to deal with emergency situationslike Covid-19 pandemic is not up to mark despite efforts ${ }^{12}$.Even the developed world has not found itself to deal this pandemic efficiently. A European country, Belgium had to request its neighboring country, Germany to share the corona patientsburden, as it was not able to cope the situation.

More than 15000 health care providers have been reported to be affected with corona infection in Pakistan. The doctors are usually considered as difficult "patients" because they need rationale of every drug suggested to themand usually start with self-medication if not well. In addition, they are more aware of complications of disease and treatment if they are suffering so are more curious.

The only vaccination available in Pakistan, till February 2021, was Sinopharm so most health workers received this type of vaccination after pre-registration. It was unfortunate that $30 \%$ of consultants suffered from COVID-19 infection when they had either complete vaccination(two doses) or few weeks after first or $2^{\text {nd }}$ dose of vaccination. As vaccines are still under trial and different companies claim around $70-80 \%$ efficacy so getting disease after vaccine is not something surprising.Another controversial issue is need of anti-viral drugs with steroids as a first drug against infection. There are variable views on need of antiviral drugs as first line therapy and issuesare still debatable. Nearly $59 \%$ were recovered with use of antiviral plus steroids whereas $41 \%$ didn't need that and recovered with intravenous antibiotics and supportive treatment.

Anxiety is not a new "term" for a consultant because he/she has entered in the tension circle since days of medical college. It is a common response to stressful conditions.During the illness anxiety was most pronounced feature stated almost by all theconsultants. It is not the issue of developing countries like Pakistan but developed world doctors are also suffering from similar issues ${ }^{13-15}$. There are different factors like high workload, long working hours, stress at work place and uncertain nature of job which can result in low immunity and higher level of stress in doctors ${ }^{16-20}$. It can result in dreadful consequences like committing suicide ${ }^{21}$ so this issueneeds to be addressed carefully. Both suspected and confirmed cases of corona infection are observed to suffer from anxiety, loneliness, depression, denial, fear and insomnia.

Being a sole earning member of family, risk of infection due to exposure from patients, family members at risk, lack of insurance policies for health care worker from government and death of a colleague from corona, all has resulted in anxiety, worriment, depression and tension specially for a doctor $22-24$. About $60 \%$ doctors in our survey were sole earning member of family with three or more dependents.Studies have showed that doctors from neighboring countries like China, India and Iran are also dealing with anxiety issues ${ }^{25-27}$. The increased positivity rate in our neighbor country India, with death toll touching around 3000 per day is worrisome and heart breaking. 
Living in isolation is not easy and living alone with fever is more difficult that's why isolation was one aspect, the recovered doctors were very concerned. In our study it was bothersome by $54.50 \%$ consultants. Eithermandatory or self-imposed quarantine, isolationhave very strong impact on person life ${ }^{20}$. All recovered doctors strongly recommended thatfollowing of SOPs and vaccination because "Prevention is better than cure" and importance of family support was recognized by all recovered doctors.

In Pakistan although very few studies have been conducted to know about anxiety and fear among health care providers, but recent study has proved that more than $50 \%$ doctors report symptoms of anxiety and depressive illness due to multiple factors ${ }^{28-30}$.

\section{CONCLUSION}

Corona pandemic has physical, psychological, social and economic effects. Everyone who suffered from it has his own insight about disease but unlike other infections, anxiety and uncertainty about future was major psychological effect which added to physical suffering of patients. Following of SOPsas precaution and developing strong family ties can provide a better support system during illness. Vaccinationwith following of SOPis only hope to decrease incidence and severity of corona infection unanimously. There is a need for doctor counselling sessions to cope with stress and anxiety issues and there should be an economical support system for families of doctors who died during their duties.

\section{REFERENCES}

1. Shereen MA, Khan S, Kazmi A, Bashir N, Siddique R. COVID-19 infection: origin, transmission, and characteristics of human coronaviruses. Journal of Advanced Research. 2020.

2. Singhal T. A review of coronavirus disease-2019 (COVID-19). The Indian Journal of Pediatrics. 2020:1-6.

3. Zhan M., Qin Y., Xue X., Zhu S. Death from Covid-19 of 23 Health Care Workers in China. N Engl J Med. 2020;382(23):2267-2268.

4. Organization WH. Coronavirus disease 2019 (COVID-19): situation report, 72.

5. Petersen E., Hui D., Hamer D.H., Blumberg L., Madoff L.C., Pollack M. Li Wenliang, a face to the frontline healthcare worker. The first doctor to notify the emergence of the SARS-CoV-2, (COVID-19), outbreak. Int J Infect Dis. 2020;93(February):205-207.

6. Saleem Z, Majeed MM, Sara Rafique S et al. COVID-19 pandemic fear and anxiety among healthcare professionals in Pakistan, 23 July 2020. doi.org/10.21203/rs.3.rs-37608/v2]

7. Corona updated, 22 April 2021: Latest news on cOVID-19 pandemic from Pakistan and around the world. www.geo.tv

8. Amber Ather B, Nikita B. Coronavirus Disease 19 (COVID-19): Implications for Clinical Dental Care. Journal of Endodontics. 2020;46(5).

9. Uddin KB. Work from home: New routines, unexplored territories, and unexpected shortcomings: Geo.tv; 2020 [updated 18th April 2020. Work from home was not a common concept for Pakistanis, but now everyone has moved towards this trend].

10. Shanafelt T, Ripp J, Trockel M. Understanding and addressing sources of anxiety among health care professionals during the COVID-19 pandemic. JAMA. 2020;323(21):213-4.

11. Nizar $H$, Chagani $P$. Analysis of health care delivery system in Pakistan and Singapore. Int J Nurs Educ. 2016;8(2):21-6.
12. Arshad S, Iqbal J, Waris H, Ismail M, Naseer A. Health care system in Pakistan: A review. Res Pharm Health Sci. 2016;2(3):211-6.

13. Mrklas K, Shalaby R, Hrabok M, Gusnowski A, Vuong W, Surood S, Urichuk L, Li D, Li X-M, Greenshaw AJ, Agyapong VIO. Prevalence of Perceived Stress, Anxiety, Depression, and Obsessive-Compulsive Symptoms in Health Care Workers and Other Workers in Alberta During the COVID-19 Pandemic: Cross-Sectional Survey. JMIR Mental Health. 2020;7(9):e22408.

14. Elhadi M, Msherghi A, Elgzairi M, Alhashimi A, Bouhuwaish A, Biala $M$, et al. Psychological status of healthcare workers during the civil war and COVID-19 pandemic: A cross-sectional study. J Psychosom Res. 2020;137:110221.

15. Amin F, Sharif S, Saeed R, Durrani N, Jilani D. COVID-19 Pandemicknowledge, Perception, Anxiety and Depression Among Frontline Doctors of Pakistan. BMC Psychiatry. 2020;20:459.

16. U.S. Department of Health and Human Services - Office of Inspector General. Hospital Experiences Responding to the COVID-19 Pandemic: Results of a National Pulse Survey March 23-27, 2020 (2020). Available online: https://oig.hhs.gov/oei/reports/oei-06-2000300.asp. (Accessed on 4 June 2020).

17. Croxson $\mathrm{CH}$, Ashdown HF, Hobbs FR. GPs' perceptions of workload in England: A qualitative interview study. $\mathrm{Br} J$ Gen Pract. 2017;67(655):e138-47.

18. Goulia P, Mantas C, Dimitroula D, Mantis D, Hyphantis T. General hospital staff worries, perceived sufficiency of information and associated psychological distress during the $\mathrm{A} / \mathrm{H} 1 \mathrm{~N} 1$ influenza pandemic. BMC Infect Dis. 2010;10:322

19. Hayes B, Prihodova L, Walsh G, Doyle F, Doherty S. What's up doc? A national cross-sectional study of psychological wellbeing of hospital doctors in Ireland. BMJ Open. 2017;7(10):e018023.

20. Qiu J, Shen B, Zhao M, Wang Z, Xie B, Xu Y. A nationwide survey of psychological distress among Chinese people in the COVID-19 epidemic: implications and policy recommendations. General psychiatry. 2020;33(2).

21. Goyal K, Chauhan P, Chhikara K, Gupta P, Singh MP. Fear of COVID 2019: First suicidal case in India! Asian journal of psychiatry. 2020;49:101989.

22. Ahmed MA, Jouhar R, Ahmed N, Adnan S, Aftab M, Zafar MS, et al. Fear and Practice Modifications among Dentists to Combat Novel Coronavirus Disease (COVID-19) Outbreak. Int J Environ Res Public Health. 2020;17(8): 2821

23. Huang L, Lei W, Xu F, Liu H, Yu L. Emotional responses and coping strategies in nurses and nursing students during COVID-19 outbreak: A comparative study. PLoS One. 2020;15(8):0237303.

24. ERSOY A. The frontline of the COVID-19 pandemic: Healthcare workers. Turkish Journal of Internal Medicine.2(2):31-2.

25. Taghizadeh F, Hassannia L, Moosazadeh M, Zarghami M Taghizadeh H, Dooki AF, et al. Anxiety and Depression in Health Workers and General Population During COVID-19 Epidemic in IRAN: A Web-Based Cross-Sectional Study. medRxiv.

26. Xiao H, Zhang Y, Kong D, Li S, Yang The effects of social support on sleep quality of medical staff treating patients with coronavirus disease 2019 (COVID-19) in January and February 2020 in China. Medical science monitor: international medical journal of experimental clinical research. 2020;26:e923549-1.

27. Cai H, Tu B, Ma J, Chen L, Fu L, Jiang Y, et al. Psychological Impact and Coping Strategies of Frontline Medical Staff in Hunan Between January and March 2020 During the Outbreak of Coronavirus Disease 2019 (COVID-19) in Hubei, China. Medical science monitor: international medical journal of experimental clinical research. 2020;26:e924171-1.

28. Bo H-X, Li W, Yang Y, Wang Y, Zhang Q, Cheung T, et al. Posttraumatic stress symptoms and attitude toward crisis mental health services among clinically stable patients with COVID-19 in China. Psychological medicine. 2020:1-2.

29. Urooj U, Ansari A, Siraj A, Khan S, Tariq H. Expectations, Fears and Perceptions of doctors during Covid19 Pakistan Journal of Medical Sciences. 2020;36(COVID19- S4).

30. Mukhtar, Sonia. 2020. Pakistanis' mental health during the COVID19. Asian Journal of Psychiatry, published online 23 April 2020. https://doi.org/10.1016/j.ajp.2020.102127 